\title{
IGF-1 Protects Neurons in the Cortex and Subventricular Zone in a Periventricular Leucomalacia Model
}

\author{
DONG-JOON KIM ${ }^{1}$, SU-YEON CHO ${ }^{1}$, SEUNG-UN KIM ${ }^{1}$, DONG-WON JO ${ }^{2}$, \\ HYO-IN HWANG ${ }^{3}$, HYE-KYOUNG SHIN ${ }^{3}$ and YONG-HYUN JUN ${ }^{3}$ \\ ${ }^{1}$ Department of Anaesthesiology and Pain medicine, Chosun University Hospital, Gwang-ju, Republic of Korea; \\ ${ }^{2}$ Graduate School of Medicine, Chosun University, Gwang-ju, Republic of Korea; \\ ${ }^{3}$ Department of Anatomy, School of Medicine, Chosun University, Gwang-ju, Republic of Korea
}

\begin{abstract}
Background/Aim: Chronic cerebral hypoperfusion affects early and mature neurons in the subventricular zone (SVZ) and cerebral cortex. Herein, we investigated the effects of insulin-like growth factor-1 (IGF-1), a neurogenesispromoting agent, on neurons in these regions in periventricular leucomalacia $(P V L)$ model rats. Materials and Methods: Following right carotid artery ligation, the rats were placed in a hypoxia chamber and injected with recombinant IGF-1 $(0.1$ and $1 \mu \mathrm{g} / \mu \mathrm{l})$. Their brain sections were immunohistochemically analysed using anti-nestin and antiNeuN antibodies. Results: The numbers of early-neuronal cells in the SVZ and mature neurons in the cerebral cortex were higher and lower, respectively, in the PVL group than in the control group. The number of NeuN-positive cells was significantly higher in the IGF-treated group than in the PVL group. Conclusion: PVL increased the number of early neuronal cells in the SVZ, reducing the survival of mature neurons in the cerebral cortex; IGF-1 reversed these effects.
\end{abstract}

Clinical syndrome in the white matter damage is associated with significant neurological outcomes (1). Immature brain is caused by reasons such as ischemic injury and infections (2, 3). Periventricular leucomalacia (PVL) occurs predominantly in premature infants. Predominant neurodevelopmental sequelae in patients with PVL are cerebral palsy, mental retardation, and behavioural deficits $(4,5)$. PVL is primarily characterised by white matter damage, but gray matter damage

This article is freely accessible online.

Correspondence to: Yong-Hyun Jun, Department of Anatomy, School of Medicine, Chosun University, 375 Seosuk-dong, DongGu, Gwangju 501-759, Republic of Korea. Tel: +82 1028862973, Fax:+82 0622341474, e-mail: jyh1483@naver.com

Key Words: PVL, IGF, cortex, SVZ, stereotactic injection. can also occur $(6,7)$. PVL leads to neuronal cell apoptosis and demyelination, causing axonal loss (8). PVL occurs in association with motor and sensory deficits $(9,10)$. However, thus far, there are no available treatments for PVL $(11,12)$.

Insulin-like growth factor-1 (IGF-1) is a single-chain peptide; it is abundantly expressed in the central nervous system (CNS) (13). In animal models, members of the IGF family play an important role in brain development and functional stability (14). IGF-1, as a potent tropic factor, has neuroprotective effects against cerebral ischemia (15). Intracranial injections of IGF-1 after hypoxia reduce the infarct volume, enhance cell survival, and improve cognitive performance $(16,17)$. These effects are caused by IGF-1 signalling, which could stimulate the neuronal cell proliferation, survival, and differentiation (18). Several studies have revealed that IGF-1 improves neurogenesis and angiogenesis in brain tissues or cells $(19,20)$.

Previous studies have shown that chronic cerebral hypoperfusion affects the number of early and mature neurons in the neurogenic zone, including the subventricular zone (SVZ) and cerebral cortex $(21,22)$. As mentioned above, IGF affects cell survival. In this study, we investigated the effects of IGF-1 on neurons in the neurogenic zones in a PVL rat model.

\section{Materials and Methods}

Animal surgery. The use of certified Sprague-Dawley (SD) rats (Damul Laboratory Animals, Daejeon, Republic of Korea) for this study was approved by the Chosun University Institutional Animal Care and Use Committee (approval no. CIACUC2019-A0031). We simulated a PVL condition based on the methods described in a previous study (23). Seven-day-old SD rats $(n=50)$ were anaesthetised with the inhalation of sevoflurane $(1.0 \%-2.0 \%$, end-tidal concentration). After shaving the fur, a midline incision was made below the anterior cervical region under aseptic conditions. The right carotid artery was exposed, and the ligature was performed using silk sutures (4/0). After the procedure, the neck was disinfected using povidone-iodine solution. After $10 \mathrm{~min}$, the rats that underwent this 
surgical procedure were placed in a hypoxia chamber $\left(8 \% \mathrm{O}_{2}\right.$ and $92 \%$ $\mathrm{N}_{2}$ conditions at $37^{\circ} \mathrm{C}$ ) for $2 \mathrm{~h}$. Rats that underwent surgery and were placed in the hypoxic chamber were assigned to the PVL group, whereas the unoperated rats were assigned to the control group $(n=50)$.

Two hours after the rats were subjected to hypoxic incubation, they underwent intracranial IGF-1 injection using stereotaxic injector (QSI/53311). The IGF-1 injection was administered as previously described (24). Briefly, recombinant IGF-1 (Genentech, San Francisco, CA, USA) at a concentration of $0.1 \mu \mathrm{g} / \mu \mathrm{l}$ and 1 $\mu \mathrm{g} / \mu \mathrm{l}$ was dissolved in sterile phosphate-buffered saline (PBS; 0.15 $\mathrm{M} ; \mathrm{pH}$ 7.4). The rats were anaesthetised with sevoflurane (1.0\%$2.0 \%$, end-tidal concentration), and the solutions were injected using a stereotaxic injector. Hamilton syringes (Hamilton Co., Reno, NV, USA) for injection were located at $1.0 \mathrm{~mm}$ posterior and $1.0 \mathrm{~mm}$ lateral to the bregma and at a $3.0 \mathrm{~mm}$ depth from the skull surface. The duration of injection was $5 \mathrm{~min}$.

Tissue preparation. Seven days after hypoxia treatment and IGF1 injection, the rat brains were harvested and fixed in $4 \%$ paraformaldehyde solution. The cerebrum was separated from the brain stems and fixed in $4 \%$ PFA at $4^{\circ} \mathrm{C}$. After one day, the cerebrum samples were washed with water, dehydrated using graded ethanol solutions, and embedded in paraffin. A series of 6-7- $\mu$ mthick sagittal sections were cut and mounted on gelatine-coated slides (Fisher Scientific USA).

Immunohistochemistry. The slides were deparaffinised and rehydrated. The slides were washed with $0.9 \% \mathrm{NaCl}$ in $0.1 \mathrm{M}$ phosphate buffer (PBS, pH 7.4). Microwave-based antigen retrieval process was performed with $0.01 \mathrm{M}$ sodium citrate buffer ( $\mathrm{pH}$ 6.0). After cooling, the slides were treated with $0.3 \%$ hydrogen peroxide for 20 min to block endogenous peroxidase. After rinsing in PBS, the slides were blocked with normal horse serum in $0.5 \%$ bovine serum albumin (BSA) solution for $30 \mathrm{~min}$ at room temperature. The slides were incubated overnight with the primary antibodies, mouse anti-hexaribonucleotide-binding protein-3 (NeuN; 1:100, Millipore, Burlington, MA, USA) and anti-nestin antibodies (1:200, Millipore), at $4^{\circ} \mathrm{C}$. On the following day, the slides were rinsed in PBS several times and incubated with secondary antibodies matched to the primary antibodies in $0.5 \%$ BSA solution for $90 \mathrm{~min}$ at room temperature. The slides were incubated with avidin-biotinperoxidase (Vector Laboratories, Burlingame, CA, USA) and immunoreactivity was visualised using the chromogenic substrate 3, 3'-diamino-benzidine (DAB). Thionin counterstaining was performed, and the slides were dehydrated and covered with DPX.

Statistical analysis. A light microscope (PrimoVert) with attached digital CCD camera was used to photograph the slides. NeuN- and Nestin-positive cells were counted in the cerebral cortex and SVZ. Each section was randomly divided into five areas, and the number of positive cells per defined square $\left(\mu \mathrm{m}^{2}\right)$ was calculated in each area. All data were analysed using Statistical Package for Social Sciences, information analysis systems (Information Analysis Systems, SPSS, IBM, Armonk, NY, USA). All measurements of the control, PVL, and Injection groups were compared using ANOVA test. $p$-values $<0.05$ were considered statistically significant.

\section{Results}

Nestin immunoreactivity. In the SVZ, the number of nestinpositive cells in the PVL group was higher than that in the control group (Figure 1). Interestingly, the number of nestinpositive cells in injection group was lower than PVL group (Figure 1). In the cerebral cortex, there was no difference in the number of nestin-positive cells between the control and PVL groups (Figure 2). The number of nestin-positive cells in Injection group was higher than PVL group in the cerebral cortex (Figure 2).

NeuN immunoreactivity. In the SVZ, there was no difference in the number of NeuN-positive cells between the control and PVL groups (Figure 3). The number of NeuN-positive cells in the cerebral cortex was lower in the PVL group than in the control group (Figure 4). The number of NeuNpositive cells in the injection group was significantly higher than that in the PVL group (Figure 4).

\section{Discussion}

We measured the number of nestin- and NeuN-positive cells in the cerebral cortex and SVZ. The number of nestin-positive cells in the SVZ was higher in the PVL group than in the control group. The number of NeuN-positive cells in the cerebral cortex was lower in the PVL group than in the control group. This reduction was achieved using IGF-1 injection.

Neuronal and glial progenitor cells, which are the sources of neurogenesis, were abundant in the SVZ (25). Especially, in the ischemic brain, these cells have been reported as important self-renewing sources for neurons and glial cells (23). The self-renewing processes, including neuron survival, axon sprouting, and neuronal enlargement and proliferation, aimed at recovering from brain injury, also known as the plasticity of the CNS, are observed in the ischemic region (26). Nestin is an intermediate neurofilament expressed by multipotential neural stem cells and precursors of neuronal and glial cells (27). In our study, the number of nestin-positive cells in the SVZ was higher in the ischemic group than in the non-ischemic group. These positive cells are considered to be sources for self-renewing processes in rats with PVL. Okoshi et al. showed strong nestin immunoreactivity of SVZ neurons in the white matter surrounding a lesion of PVL (28). It is suggested that the early stage of neurogenesis is triggered in the SVZ of the rats from the PVL group.

In our study, the numbers of early neuronal cells and nestin-positive cells were increased in the SVZ in the rats from the PVL group. The numbers of mature neuronal cells and NeuN-positive cells were reduced in the cerebral cortex in the rats from this group. The early neuronal cells in the SVZ migrated to the cerebral cortex; neurogenesis was triggered, but cell survival was not affected (29). This phenomenon was reversed by IGF-1 administration. As mentioned in the introduction, IGF-1 plays a major role in neuronal cell survival and maturation (14, 30). IGF-I activates the MAPK pathway, especially, the extracellular 

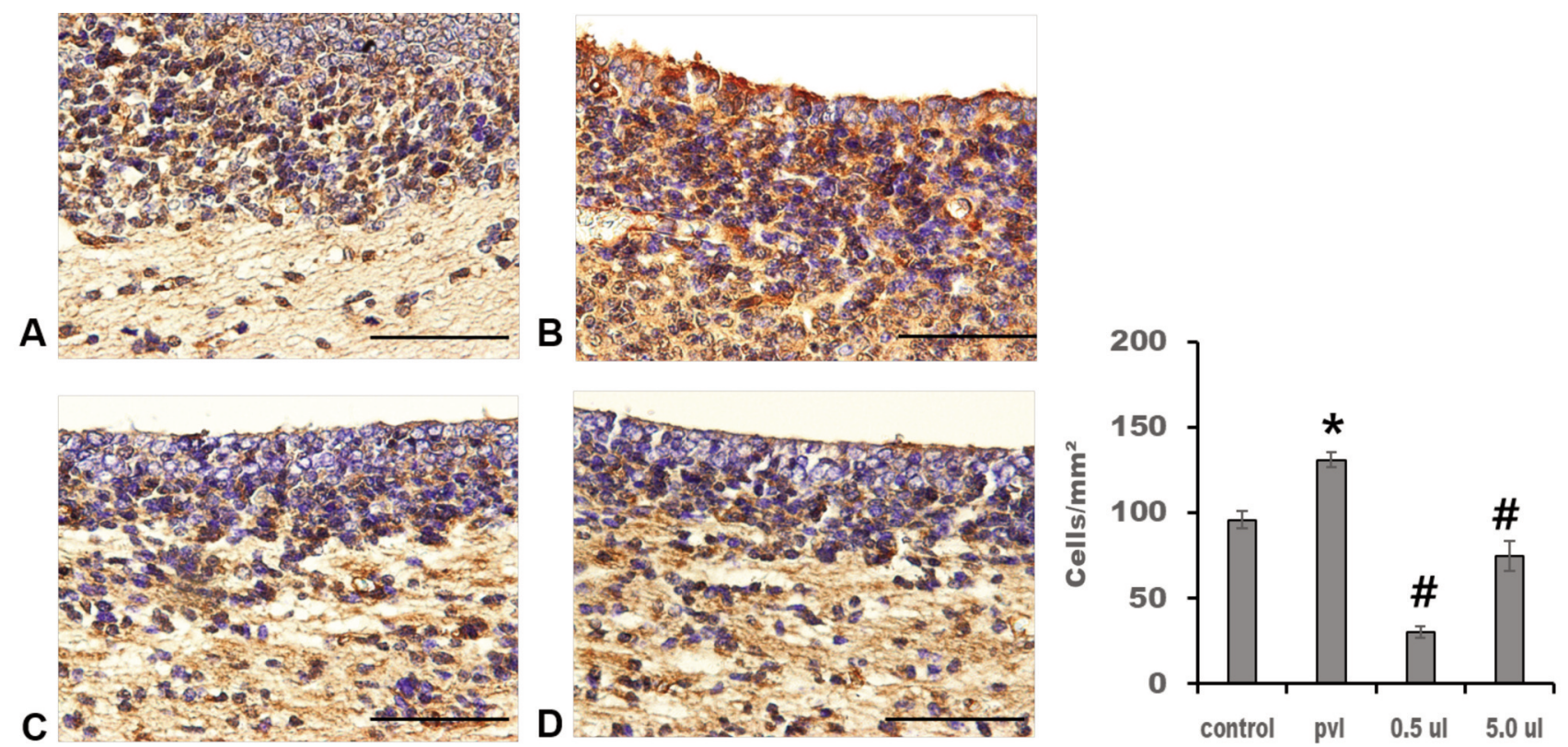

Figure 1. Representative photographs and density of nestin-immunoreactivity cells in the subventricular zone. (A): Control group, (B): PVL group, $(C)$ : injection group $(0.1 \mu \mathrm{g} / \mu \mathrm{l}),(D)$ : injection group $(1 \mu \mathrm{g} / \mu \mathrm{l})$. The data are expressed as mean and SEM values. ${ }^{*} p<0.05$ (compared control), ${ }^{\#} p<0.05$ (compared $P V L$ ). Scale bars $=100 \mu \mathrm{m}$.
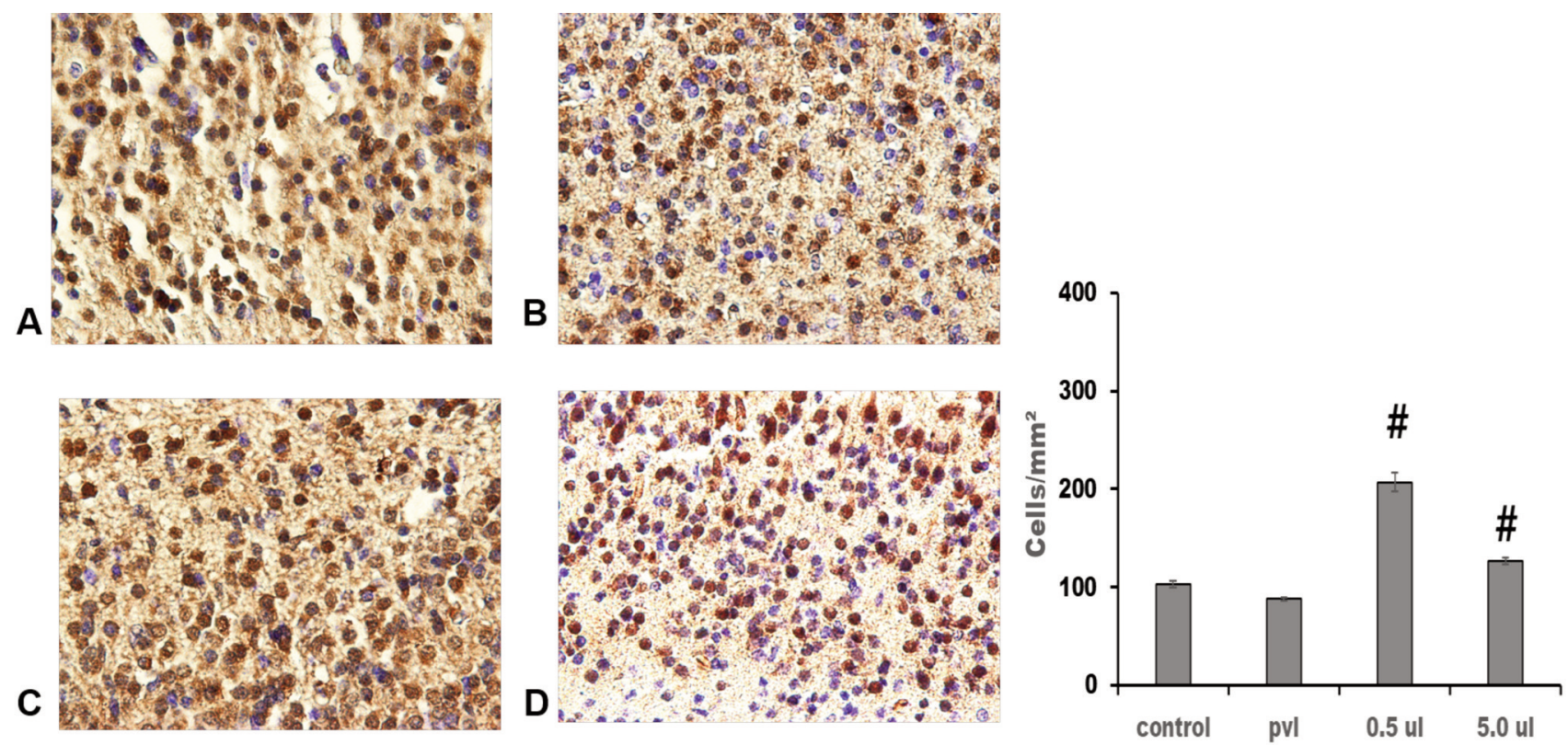

Figure 2. Representative photographs and density of nestin-immunoreactivity cells in the cerebral parietal cortex. (A): Control group, (B): $P V L$ group, $(C)$ : injection group $(0.1 \mu \mathrm{g} / \mu \mathrm{l}),(D)$ : injection group $(1 \mu \mathrm{g} / \mu \mathrm{l})$. The data are expressed as mean and SEM values. ${ }^{*} p<0.05($ compared control), ${ }^{\#} p<0.05$ (compared to PVL). Scale bars $=100 \mu \mathrm{m}$.

signal-regulated kinase (ERK) pathway, to regulate cell survival and neuronal plasticity (31). In some cells, the PI3K/Akt pathway is activated by IGF-1 to enhance cell survival (32).
We studied the effects of high and low doses of IGF-1 on PVL in rats. Interestingly, in our study, the effects of both high and low doses of IGF-1 on PVL were similar. The numbers of mature neuronal cells were induced in the 

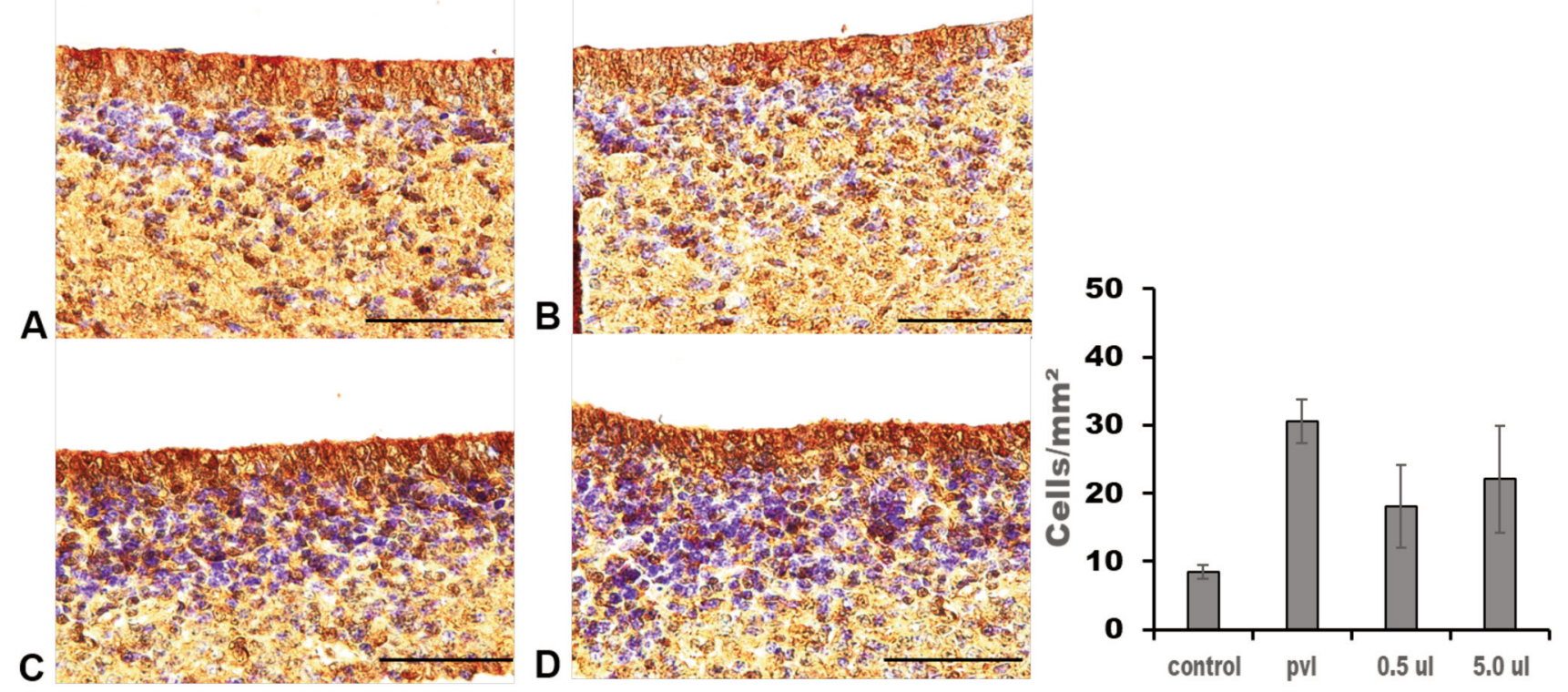

Figure 3. Representative photographs and density of NeuN-immunoreactivity cells in the subventricular zone. (A): Control group, (B): PVL group, $(C)$ : injection group $(0.1 \mu \mathrm{g} / \mu \mathrm{l})$, (D): injection group $(1 \mu \mathrm{g} / \mu \mathrm{l})$. The data are expressed as mean and SEM values. ${ }^{*} p<0.05$ (compared to control), ${ }^{\#} p<0.05$ (compared to $P V L$ ). Scale bars $=100 \mu \mathrm{m}$.
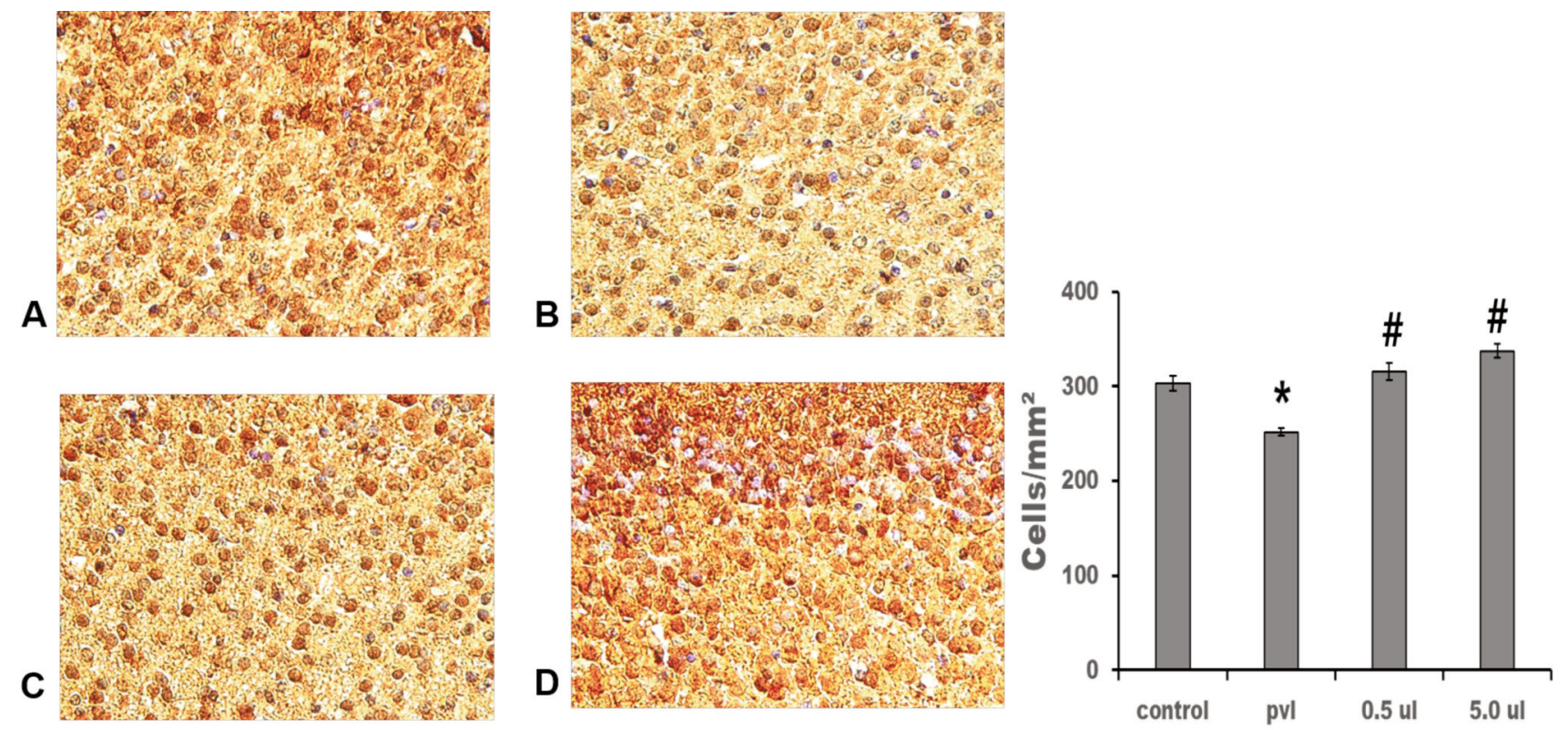

Figure 4. Representative photographs and density of NeuN-immunoreactivity cells in the cerebral parietal cortex. $(A)$ : Control group, $(B): P V L$ group, $(C)$ : injection group $(0.1 \mu \mathrm{g} / \mu \mathrm{l}),(D)$ : injection group $(1 \mu \mathrm{g} / \mu \mathrm{l})$. The data are expressed as mean and SEM values. ${ }^{*} p<0.05$ (compared to control), ${ }^{p} p<0.05$ (compared to PVL). Scale bars $=100 \mu \mathrm{m}$.

cerebral cortex in the rats from high and low doses of IGF1 injection group. Several studies have revealed discrepant effects of IGF depending on its dose. Some studies have reported that IGF-1 protects against ischemic damage only at a high dose (33). Controversially, Cao et al. showed that IGF-1 prevented the loss of myelin and glial cells after hypoxia in foetal sheep only at low doses (34). However, A previous study that was similar to our study showed that 
hypoxia and infection co-existed and interacted with each other (35). Inflammatory responses caused by the intracerebral injection of lipopolysaccharide (LPS) is similar to the pathology observed in case of PVL (35). Several studies have reported that IGF-1 exhibits neuroprotective effects against ischemic damage and neuroinflammation (15, 36). We suggest that IGF-1 has protective effects against either hypoxia or inflammation in the developing rat brain.

PVL led to increase in the number of early neuronal cells in the SVZ and reduction of survival of mature neurons in the cerebral cortex. These effects were reversed by IGF-1 injection.

\section{Conflicts of Interest}

The Authors declare that they have no competing interests.

\section{Authors' Contributions}

YHJ designed the study. DJK and HLS participated in the surgical procedures. SYC, SUK, and DWJ analysed the obtained data. HIH performed the immunohistochemical analyses. All authors approved the final manuscript.

\section{Acknowledgements}

This study was supported by research funds from the Chosun University (2016).

\section{References}

1 Zhang DS, Bai XH, Chen DP, Mu DZ and Chen J: intracerebral transplantation of human umbilical cord-derived mesenchymal stem cells in neonatal rat model of hypoxic-ischemic brain damage: Protective effect to injured brain. Zhongguo Dang Dai Er Ke Za Zhi 16(9): 927-932, 2014. PMID: 25229962. DOI: 10.7499/j.issn.1008-8830.2014.09.013

2 Northington FJ, Ferriero DM, Graham EM, Traystman RJ and Martin LJ: Early neurodegeneration after hypoxia-ischemia in neonatal rat is necrosis while delayed neuronal death is apoptosis. Neurobiol Dis 8(2): 207-219, 2001. PMID: 11300718. DOI: $10.1006 /$ nbdi.2000.0371

3 Wixey JA, Chand KK, Colditz PB and Bjorkman ST: Review: Neuroinflammation in intrauterine growth restriction. Placenta 54: 117-124, 2017. PMID: 27916232. DOI: 10.1016/j.placenta. 2016.11.012

4 Tüzün F, Gencpınar P, Ozbal S, Dilek M, Ergur BU, Duman N, Ozkan $\mathrm{H}$ and Kumral A: Neuroprotective effect of neotrofin in a neonatal rat model of periventricular leukomalacia. Neurosci Lett 520(1): 6-10, 2012. PMID: 22579826. DOI: 10.1016/ j.neulet.2012.04.076

5 Blumenthal I: Periventricular leucomalacia: A review. Eur J Pediatr 163(8): 435-442, 2004. PMID: 15179510. DOI: 10.1007/s00431-004-1477-y

6 Pierson CR, Folkerth RD, Billiards SS, Trachtenberg FL, Drinkwater ME, Volpe JJ and Kinney HC: Gray matter injury associated with periventricular leukomalacia in the premature infant. Acta Neuropathol 114(6): 619-631, 2007. PMID: 17912538 DOI: $10.1007 / \mathrm{s} 00401-007-0295-5$

7 Webber DJ, van Blitterswijk $M$ and Chandran S: Neuroprotective effect of oligodendrocyte precursor cell transplantation in a long-term model of periventricular leukomalacia. Am J Pathol 175(6): 2332-2342, 2009. PMID: 19850891. DOI: 10.2353/ajpath.2009.090051

8 Goyal H, Singh N, Gurjar OP and Tanwar RK: Radiation induced demyelination in cervical spinal cord of the head and neck cancer patients after receiving radiotherapy. J Biomed Phys Eng 10(1): 16, 2020. PMID: 32158706. DOI: 10.31661/jbpe.v0i0.1055

9 Spittle A, Orton J, Anderson PJ, Boyd R and Doyle LW: Early developmental intervention programmes provided post hospital discharge to prevent motor and cognitive impairment in preterm infants. Cochrane Database Syst Rev 11: Cd005495, 2015. PMID: 26597166. DOI: 10.1002/14651858.CD005495.pub4

10 Carbajal-Valenzuela CC, Santiago-Rodríguez E, Harmony T and Fernández-Bouzas A: Visual evoked potentials in infants with diffuse periventricular leukomalacia. Clin EEG Neurosci 45(4): 269-273, 2014. PMID: 24615931. DOI: 10.1177/1550059413515655

11 Hocaoğlu N, Murat N, Micılı SC, Aydın B, Ergür BU and Kalkan Ş: Correlation between amitriptyline-induced cardiotoxic effects and cardiac $\mathrm{s} 100 \mathrm{~b}$ protein in isolated rat hearts. Balkan Med J 33(6): 681-687, 2016. PMID: 27994924. DOI: 10.5152/balkanmedj.2016.150435

12 Hirose-Ikeda M, Chu B, Zhao P, Akil O, Escalante E, Vergnes L, Cepeda $\mathrm{C}$ and Espinosa-Jeffrey A: Trophic factors are essential for the survival of grafted oligodendrocyte progenitors and for neuroprotection after perinatal excitotoxicity. Neural Regen Res 15(3): 557-568, 2020. PMID: 31571668. DOI: 10.4103/1673-5374.266066

13 Gong X, Ma M, Fan X, Li M, Liu Q, Liu X and Xu G: Downregulation of igf-1/igf- $1 \mathrm{r}$ in hippocampus of rats with vascular dementia. Neurosci Lett 513(1): 20-24, 2012. PMID: 22342912. DOI: $10.1016 /$ j.neulet.2012.01.077

14 Dyer AH, Vahdatpour C, Sanfeliu A and Tropea D: The role of insulin-like growth factor 1 (igf-1) in brain development, maturation and neuroplasticity. Neuroscience 325: 89-99, 2016. PMID: 27038749. DOI: 10.1016/j.neuroscience.2016.03.056

15 Chang HC, Yang YR, Wang PS, Kuo CH and Wang RY: The neuroprotective effects of intramuscular insulin-like growth factor-i treatment in brain ischemic rats. PLoS One 8(5): e64015, 2013. PMID: 23717526. DOI: 10.1371/journal.pone.0064015

16 Farias Quipildor GE, Mao K, Hu Z, Novaj A, Cui MH, Gulinello M, Branch CA, Gubbi S, Patel K, Moellering DR, Tarantini S, Kiss T, Yabluchanskiy A, Ungvari Z, Sonntag WE and Huffman DM: Central igf-1 protects against features of cognitive and sensorimotor decline with aging in male mice. Geroscience 41(2): 185-208, 2019. PMID: 31076997. DOI: 10.1007/s11357-019-00065-3

17 Tien LT, Lee YJ, Pang Y, Lu S, Lee JW, Tseng CH, Bhatt AJ, Savich RD and Fan LW: Neuroprotective effects of intranasal igf1 against neonatal lipopolysaccharide-induced neurobehavioral deficits and neuronal inflammation in the substantia nigra and locus coeruleus of juvenile rats. Dev Neurosci 39(6): 443-459, 2017. PMID: 28787734. DOI: $10.1159 / 000477898$

18 Li X, Yao J, Wu J, Du X, Jing W and Liu L: Roles of prf and igf-1 in promoting alveolar osteoblast growth and proliferation and molecular mechanism. Int J Clin Exp Pathol 11(7): 32943301, 2018. PMID: 31949704. 
19 Nieto-Estévez V, Defterali Ç and Vicario-Abejón C: Igf-i: A key growth factor that regulates neurogenesis and synaptogenesis from embryonic to adult stages of the brain. Front Neurosci 10: 52, 2016. PMID: 26941597. DOI: 10.3389/fnins.2016.00052

20 Ruan L, Wang B, ZhuGe Q and Jin K: Coupling of neurogenesis and angiogenesis after ischemic stroke. Brain Res 1623(166-173, 2015. PMID: 25736182. DOI: 10.1016/j.brainres.2015.02.042

21 Chung Y, Cho H, Jo GH and Jun Y: Hypoxia of rats subjected to carotid artery ligation results in impaired neurogenesis and reduced number of cortical neurons. In Vivo 33(2): 441-445, 2019. PMID: 30804123. DOI: 10.21873 /invivo. 11492

22 So K, Chung Y, Yu SK and Jun Y: Regional immunoreactivity of pax6 in the neurogenic zone after chronic prenatal hypoxia. In Vivo 31(6): 1125-1129, 2017. PMID: 29102934. DOI: 10.21873/invivo. 11178

23 Mao FX, Li WJ, Chen HJ, Qian LH and Buzby JS: White matter and svz serve as endogenous sources of glial progenitor cells for self-repair in neonatal rats with ischemic pvl. Brain Res 1535: 3851, 2013. PMID: 23994449. DOI: 10.1016/j.brainres.2013.08.006

24 Lin S, Fan LW, Pang Y, Rhodes PG, Mitchell HJ and Cai Z: Igf1 protects oligodendrocyte progenitor cells and improves neurological functions following cerebral hypoxia-ischemia in the neonatal rat. Brain Res 1063(1): 15-26, 2005. PMID: 16259966. DOI: 10.1016/j.brainres.2005.09.042

25 Liang H, Zhao H, Gleichman A, Machnicki M, Telang S, Tang S, Rshtouni M, Ruddell J and Carmichael ST: Region-specific and activity-dependent regulation of svZ neurogenesis and recovery after stroke. Proc Natl Acad Sci U S A 116(27): 1362113630, 2019. PMID: 31196958. DOI: 10.1073/pnas.1811825116

26 Sozmen EG, Kolekar A, Havton LA and Carmichael ST: A white matter stroke model in the mouse: Axonal damage, progenitor responses and mri correlates. J Neurosci Methods 180(2): 261-272, 2009. PMID: 19439360. DOI: 10.1016/j.jneumeth.2009.03.017

27 Messam CA, Hou J, Berman JW and Major EO: Analysis of the temporal expression of nestin in human fetal brain derived neuronal and glial progenitor cells. Brain Res Dev Brain Res 134(1-2): 87-92, 2002. PMID: 11947939. DOI: 10.1016/s01653806(01)00325-X

28 Okoshi Y, Mizuguchi M, Itoh M, Oka A and Takashima S: Altered nestin expression in the cerebrum with periventricular leukomalacia. Pediatr Neurol 36(3): 170-174, 2007. PMID: 17352950. DOI: 10.1016/j.pediatrneurol.2006.12.007

29 Lois C and Alvarez-Buylla A: Proliferating subventricular zone cells in the adult mammalian forebrain can differentiate into neurons and glia. Proc Natl Acad Sci USA 90(5): 2074-2077, 1993. PMID: 8446631. DOI: 10.1073/pnas.90.5.2074
30 Sohda M, Kato H, Miyazaki T, Nakajima M, Fukuchi M, Manda $\mathrm{R}$, Fukai Y, Masuda $\mathrm{N}$ and Kuwano $\mathrm{H}$ : The role of insulin-like growth factor 1 and insulin-like growth factor binding protein 3 in human esophageal cancer. Anticancer Res 24(5a): 3029-3034, 2004. PMID: 15517912.

31 Yao J, Ke J, Zhou Z, Tan G, Yin Y, Liu M, Chen J and Wu W: Combination of hgf and igf-1 promotes connexin 43 expression and improves ventricular arrhythmia after myocardial infarction through activating the mapk/erk and mapk/p38 signaling pathways in a rat model. Cardiovasc Diagn Ther 9(4): 346-354, 2019. PMID: 31555539. DOI: 10.21037/cdt.2019.07.12

32 Yang L, Wang H, Liu L and Xie A: The role of insulin/igf$1 / \mathrm{pi} 3 \mathrm{k} / \mathrm{akt} / \mathrm{gsk} 3 \beta$ signaling in parkinson's disease dementia. Front Neurosci 12: 73, 2018. PMID: 29515352. DOI: $10.3389 /$ fnins .2018 .00073

33 Simonishvili S, Jain MR, Li H, Levison SW and Wood TL: Identification of bax-interacting proteins in oligodendrocyte progenitors during glutamate excitotoxicity and perinatal hypoxia-ischemia. ASN Neuro 5(5): e00131, 2013. PMID: 24195677. DOI: 10.1042/an20130027

34 Cao Y, Gunn AJ, Bennet L, Wu D, George S, Gluckman PD, Shao XM and Guan J: Insulin-like growth factor (igf)-1 suppresses oligodendrocyte caspase-3 activation and increases glial proliferation after ischemia in near-term fetal sheep. J Cereb Blood Flow Metab 23(6): 739-747, 2003. PMID: 12796722. DOI: 10.1097/01.Wcb.0000067720.12805.6f

35 Campbell LR, Pang Y, Ojeda NB, Zheng B, Rhodes PG and Alexander BT: Intracerebral lipopolysaccharide induces neuroinflammatory change and augmented brain injury in growth-restricted neonatal rats. Pediatr Res 71(6): 645-652, 2012. PMID: 22337231. DOI: 10.1038/pr.2012.26

36 Labandeira-Garcia JL, Costa-Besada MA, Labandeira CM, Villar-Cheda B and Rodríguez-Perez AI: Insulin-like growth factor-1 and neuroinflammation. Front Aging Neurosci 9: 365, 2017. PMID: 29163145. DOI: 10.3389/fnagi.2017.00365

Received September 28, 2020

Revised October 13, 2020

Accepted October 14, 2020 